\title{
Development of low alcoholic naturally carbonated fermented debittered beverage from grapefruit (Citrus paradisi)
}

\author{
G. Pandove ${ }^{1}$, P. Sahota ${ }^{2}$ and N.Gupta ${ }^{1^{*}}$ \\ ${ }^{1}$ Punjab Agricultural University, Regional Research Station, Bathinda-151001(Punjab), INDIA \\ ${ }^{2}$ Department of Microbiology, Punjab Agricultural University, Ludhiana-141004 (Punjab), INDIA \\ *Corresponding author.E-mail: navjotgupta@pau.edu
}

Received: September 10, 2015; Revised received: May 11, 2016; Accepted: July 25, 2016

\begin{abstract}
A pure yeast Clavispora lusitaniae, isolated from whey beverage, phenotypically characterized and molecularly characterized by sequencing of D1/D2 domain of 26S rRNA and Internal Transcribed Spacer (ITS) region was used to produce low alcoholic naturally carbonated fermented debittered beverage from Grapefruit. $C$. lusitaniae produces enzyme naringinase. This enzyme is a mixture of $\alpha$-L-rhamnosidase and $\beta$-D-glucosidase. The bitter component in citrus fruit, naringin can be hydrolyzed by $\alpha$-L-rhamnosidase to rhamnose and prunin then by $\beta$ glucosidase to glucose and naringenin. The freshly prepared fermented Grapefruit beverage had TSS $14{ }^{\circ} \mathrm{B}, \mathrm{pH} 4.7$, acidity $0.26 \%$, brix acid ratio 53.85 , total sugars $11.6 \%$, reducing sugars $3.34 \%$, ascorbic acid $21.9 \mathrm{mg} / 100 \mathrm{ml}$, naringin $643.2 \mathrm{ppm}$, alcohol $0.00 \%(\mathrm{v} / \mathrm{v}), \mathrm{CO}_{2} 0.00$ bar and total yeast count 5.83 (Log no.of cells/ml). Physico-chemical changes recorded after three months of storage at refrigerated temperature revealed TSS $12.0 \mathrm{~B}, \mathrm{pH} 4.2$, acidity $0.54 \%$, brix acid ratio 22.22 , total sugars $8.97 \%$, reducing sugars $1.94 \%$, ascorbic acid $18.45 \mathrm{mg} / 100 \mathrm{ml}$, naringin $365.2 \mathrm{ppm}$, alcohol $0.76 \%(\mathrm{v} / \mathrm{v}), \mathrm{CO}_{2} 1.35$ bar and total yeast count 8.54 (Log no.of cells/ml). Naturally produced $\mathrm{CO}_{2}$ by $C$. lusitaniae during fermentation adds effervescence, sparkle, tangy taste to the beverage in addition to its antimicrobial properties. Thus bio-enzymatic debittering by $C$. lusitaniae may become the new direction of citrus juice processing in the future, due to its economical viability with strong ability to remove the bitter taste from citrus juice beverage.
\end{abstract}

Keywords: Clavispora lusitaniae, Economical viability, Internal transcribed spacer, Sequencing

\section{INTRODUCTION}

India is the world's second largest producer of fruits (57.73 million tonnes) with its projected value touching 98 Mt by the year 2020-2021 (Banerjee, 2009). The citrus occupies an area of about 0.81 Mha with production of $7.50 \mathrm{Mt}$ and yield of $9.26 \mathrm{t} / \mathrm{ha}$ and ranks fifth in its production in the world (Anonymous, 2010). In the past three years, Punjab has recorded over 20 tonnes of citrus fruit per hectare while the national average productivity during the same period was just 8.82 tonnes per hectare, less than half of Punjab's production (Anonymous ,2013).

The health benefits of citrus fruit juices have been attributed to the presence of bioactive and antioxidant compounds such as ascorbic acid (53mg/100g), flavonoids, limonoids, coumarins and essential vitamins; folates $(30 \mu \mathrm{g})$, Niacin $(0.282 \mathrm{mg})$, Panthothenic acid $(0.25 \mathrm{mg})$, Pyridoxine $(0.060 \mathrm{mg})$, Riboflavin $(0.040 \mathrm{mg})$, Thiamine (0.1mg), Vitamin A (225 IU), Vitamin E (0.18mg) per $100 \mathrm{~g}$. Citrus fruits also contains electrolytes in the form of sodium $(3-4 \mathrm{mg} / \mathrm{ml})$, potassium $(300 \mathrm{mg}$ in $178 \mathrm{ml}$ juice) and minerals like calcium (40mg), copper (39mg), iron $(0.1 \mathrm{mg})$, magnesium (10mg), manganese (0.024mg), zinc $(0.8 \mathrm{mg})$ and $\beta$-carotenoides $(71 \mu \mathrm{g})$ per $100 \mathrm{~g}$ (USDA National Nutrient Database).

The grapefruit (Citrus paradisi) is the fourth most economically important citrus fruit in the world. It is an excellent source of many nutrients, phytochemicals, vitamin $\mathrm{C}$, and fiberpectin with pink and red hues that contain the beneficial antioxidant lycopene (Silver et al., 2011). The nutritional and therapeutic value of citrus fruits provides ample scope for processing into a value added fermented product with retention of organoleptic properties, nutritional attributes, characteristics sensory properties, flavour, aroma, texture and long shelf life. But its tissues containing flavonoids like hesperidin, limonin, naringin may cause interference during the citrus fruit juice processing and cause for the bitter taste (Konno et al., 1982). Naringin is the major component in grapefruit with very bitter taste and a threshold of $20 \mathrm{mg} \mathrm{Kg}^{-1}$ in water and detectable limit less than $1.5 \mathrm{mg} \mathrm{Kg}^{-1}$ (Chandler and Nicol, 1975). IThe enzymatic debittering technology is regarded as the most promising method with the advantages of high specificity and efficiency, and a convenient operation for removing the bitterness in large-scale commercial production (Yadav et al., 2010). Naringin 
can be hydrolyzed by the $\alpha$-L-rhamnosidase activity into rhamnose and prunin (4,5,7-trihydroxyflavonone7-glucopyranoside), in which prunin can be further hydrolyzed by the $\beta$-D-glucosidase activity into glucose and naringenin (4,5,7-trihydroxyflavonone) (Chien et al., 2001).

The novel yeast isolate Clavispora lusitaniae mutant has been isolated and characterized molecularly and biochemically in the Department of Microbiology, Punjab Agricultural University, which produces naringinase (Jairath et al., 2012, Sahota et al., 2013) The enzyme naringinase is composed of $\alpha$-L-rhamnosidase (EC 3.2.1.40) and $\beta$-D-glucosidase (EC 3.2.1.21) (Singh et $a l ., 2015$ ).This yeast culture has potential to produce less than $1 \%$ alcohol and 1.5 bar pressure of carbon dioxide (Sahota and Pandove, 2010).

Hence, to safeguard the interest of progressive horticulturists, the utilization of Grapefruits for the production of beverages in the form of low alcoholic naturally carbonated fermented debittered beverages appear to be economically viable and value added technologies.The present work aims to redress the problem of tapping the bitterness by exploiting the potential of $C$. lusitaniae and thus making the fruit available throughout the year for the consumers to harness their health promotional properties.

\section{MATERIALS AND METHODS}

Fruits : Grapefruit var. Marsh Seedless was procured from Punjab Agricultural University, Regional Research Station, Bathinda-151001, Punjab, India.

Extraction of juice: Healthy fruits were washed with chlorinated water and cut into two halves, deseeded and juice was extracted aseptically using Electronic juicer.

Yeast culture: Yeast culture $C$. lusitaniae having the potential to produce less than $1 \%$ alcohol and 1.5 bar pressure of carbon dioxide (Sahota and pandove, 2010) was obtained from the Department of Microbiology, PAU, Ludhiana. It has been isolated from whey beverage, phenotypically characterized and D1/D2 domain of 26S rRNA and Internal Transcribed Spacer (ITS) region sequenced (Jaitath et al., 2012)

Inoculum preparation: Grapefruit juice was diluted with water (boiled and cooled), and brix adjusted to $14^{\circ} \mathrm{B}$ by adding sugar solution. A loopful of $24 \mathrm{hrs}$ old yeast culture was transferred to juice in $250 \mathrm{ml}$ Erlenmeyer flask and incubated at $20 \pm 5^{\circ} \mathrm{C}$ for $24 \mathrm{hrs}$ to achieve concentration $10^{7}-10^{8} \mathrm{cfu} / \mathrm{ml}$, and used as starter culture.

Preparation of sugar solution: Granulated sucrose was procured from local market of Bathinda.Punjab, India The sugar solution was prepared by boiling $(500 \mathrm{~g})$ granulated sucrose in one litre of water for $10 \mathrm{~min}$ and then allowed to cool at room temperature and stored aseptically in glass bottles.

Physico-chemical analysis of grapefruit: Five fruits of uniform size were taken for physico- chemical analysis of grapefruit.The physico-chemical analysis, TSS, pH, acidity, brix acid ratio, naringin, total sugars, reducing sugars, ascorbic acid and percentage juice yield of graprfruit was done.

Preparation of low alcoholic naturally carbonated fermented dibbitered grapefruit beverage: The raw grapefruit juice was diluted with water (boiled and cooled, 40\% juice) and sugar solution was added to achieve the required TSS $14.0^{\circ} \mathrm{B}$, followed by the culture @ $0.5 \%$ (v/v). It was incubated at $20 \pm 5^{\circ} \mathrm{C}$ for $36 \mathrm{hrs}$. The beverage was refrigerated for $24 \mathrm{hrs}$, siphoned, bottled and stored at refrigerated temperature.

Quality evaluation and shelf life determination of grapefruit beverage: Shelf life of low alcoholic naturally carbonated fermented debittered grapefruit beverage, stored at refrigerated temperature $\left(4^{\circ} \mathrm{C}\right)$ was studied and evaluated fortnightly for physico-chemical, microbiological and sensory qualities. The data was replicated thrice.

Physicochemical, microbiological and organoleptic analysis: Percentages of total soluble solids (\%TSS) in juice and beverage were determined by using Erma hand refractometer of $0-32^{\circ} \mathrm{B}$ (Erma, Tokyo, Japan). $\mathrm{pH}$ of the juice was determined using a digital $\mathrm{pH}$ meter (ECIL, Hyderabad, type 101). Total acidity expressed as citric acid was estimated following the procedure of AOAC (1999). Brix acid ratio was calculated by dividing TSS value by total acidity of the juice and carbonated beverage. Total sugars were estimated by phenol-sulphuric acid method of Dubois using glucose as standard (1956). Reducing sugars were estimated by the method of Miller (1959). The titration method using 2,6-dichlorophenol indophenol dye was used to estimate ascorbic acid AOVC (1996). Naringin was estimated by the method of Davis (1947). Carbon dioxide volume in beverage bottles was determined by piercing device $\left(\mathrm{CO}_{2}\right.$ tester). Total yeast count was enumerated on GYE agar by serial plate dilution method. The organoleptic evaluation of grapefruit beverages was done on the basis of appearance, color, aroma, bouquet, body, flavour, astringency and overall acceptability by a panel of five judges. Consumer acceptance for the products was evaluated on a nine point "Hedonic scale 2."

Statistical analysis: The test of mean comparison according to critical difference (CD) was applied. Significance level was accepted at $\mathrm{p} \leq 0.05$. The data of 3 replications was analyzed statistically by using GSTAT 04 and CPCS1 software developed by Maths, Statistics and Physics Department, PAU, Ludhiana.

\section{RESULTS AND DISCUSSION}

Physico -chemical characteristics grapefruit (Citrus paradisi): The acceptability and higher sensory score of beverages depends upon on physico-chemical properties including appearance, flavour, acidity and TSS. There may be changes in the physico-chemical characteristics and loss of some compounds that impart flavour and aroma to the beverages during pasteurization and storage. The physico-chemical composition of Grapefruit juice 
Table 1: Physicochemical characteristics of Grapefruit juice.(C. paradisi).

\begin{tabular}{ll}
\hline Parameters & Value \\
\hline TSS $\left({ }^{\circ} \mathrm{B}\right)$ & 7.7 \\
Acidity $(\%)$ & 0.35 \\
pH & 4.6 \\
Brix-acid ratio & 22 \\
Naringin (ppm) & 752 \\
Total sugars $(\%)$ & 14.5 \\
Reducing sugars $(\%)$ & 3.5 \\
Ascorbic acid (mg/100ml) & 33.5 \\
juice yield $(\%)$ & $39.33 \%$ \\
\hline
\end{tabular}

*Five fruits of uniform size were taken for physico- chemical analysis of grapefruit

evaluated on the basis of chemical analysis is: TSS $7.7^{\circ} \mathrm{B}$, titrable acidity 0.35 per cent, $\mathrm{pH} 4.6$, Brix acid ratio 22.0, total sugars 14.5 per cent, reducing sugars 3.5 per cent, ascorbic acid $33.5 \mathrm{mg} / 100 \mathrm{~g}$, naringin $752 \mathrm{ppm}$, and percentage juice yield from Grapefruit was $39.33 \%$ (Table 1).

Shelf life studies of grapefruit $(C$. paradisi) beverage: Shelf life of low alcoholic naturally carbonated fermented debittered Grapefruit beverage stored at refrigerated temperature $\left(4^{\circ} \mathrm{C}\right)$ was studied for a period of 90 days and evaluated fortnightly for physico-chemical, microbiological and organoleptic qualities.

Effect of storage time on physico-chemical and microbiological properties of beverage: The results of Grapefruit beverage (Table 2) showed significant decrease in brix from $14.0^{\circ} \mathrm{B}$ to $12.0^{\circ} \mathrm{B}$ and brix acid ratio from 53.85 to 22.22. Similar results have been reported in lime juice (Sarolia and Mukherjee, 2002), kinnow sera, cane and kinnow cane juice (Khandelwal et al., 2006) and ready to serve mandarin (Citrus reticulata) diet drink (Ahmed et al., 2008).

The $\mathrm{pH}$ of the beverage also decreased from 4.7 to 4.2 with subsequent increase in the acidity from 0.26 to 0.54 per cent during storage period of 90 days. This decrease in $\mathrm{pH}$ and increase in acidity was attributed to formation of acidic compounds by degradation of reducing sugars (Akhtar et al., 2010). The increase in acidity may be ascribed to rise in the concentration of weakly ionized acid and their salts during storage (Akhtar et al.,2010).

The percentage decrease in total sugars with storage period of 90 days was 22.67 percent as it decreased from 11.60 to 8.97 percent at the end of 90 days while the percent decrease for the reducing sugars was 41.92 percent as it decreased gradually from 3.34 to 1.94 percent after 90 days. The sugars in citrus are mainly glucose, laevulose and sucrose. Similar results were also observed by Jairath (2012) for preparation of amla beverage.

The percentage decrease in the ascorbic acid was found to be 15.75 percent as it decreased from 21.90 to 18.45 percent during storage period of 90 days, this may be due to photo-oxidation of ascorbic acid as it is a strong reducing

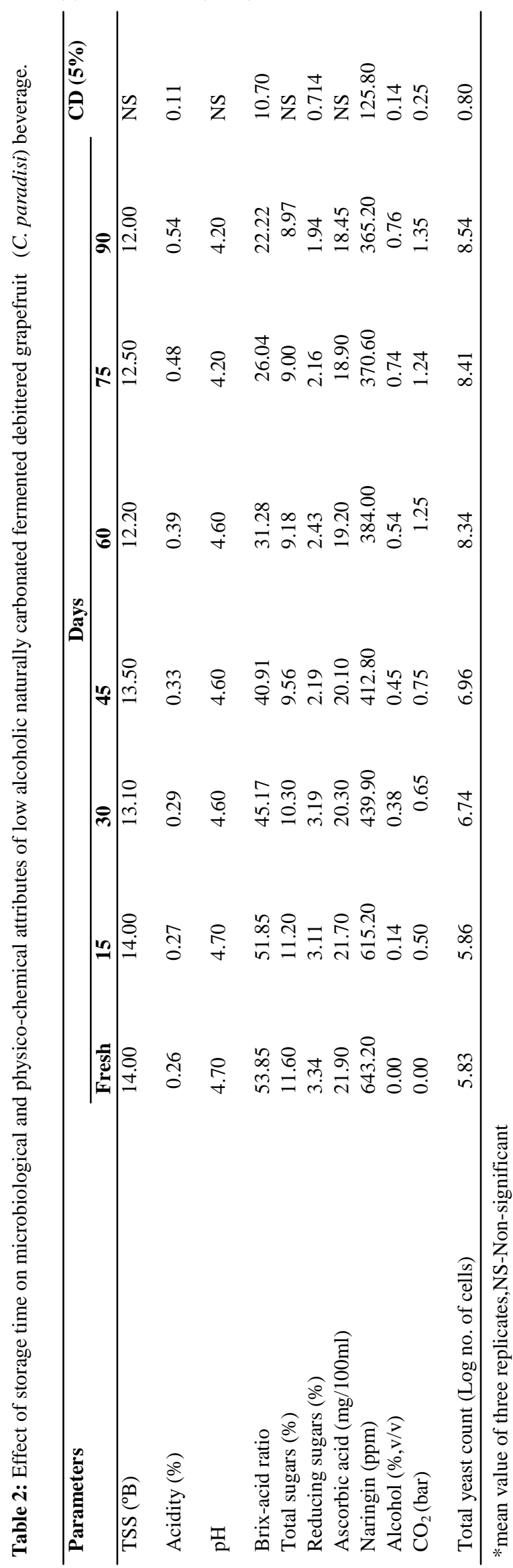


agent, readily losing hydrogen atom to become dehydroascorbic acid and finally hydrolysed losing its vitamin activity to ketogluconic acid. The decrease of ascorbic acid (vitamin $\mathrm{C}$ ) in beverage during storage results from oxidation of ascorbic acid by ascorbic acid oxidase due to a combined effect of oxygen and light (Jairath et al., 2012).

The decrease in naringin was 43.22 percent as it decreased gradually from 643.20 to 365.20 ppm after 90 days. This may be due to the production of enzyme naringinase by $C$. lusitaniae,(Sahota et al., 2013) The enzyme naringinase is composed of $\alpha$-L-rhamnosidase (EC 3.2.1.40) and $\beta$-D-glucosidase (EC 3.2.1.21) (Singh et al., 2015) .

The alcohol production started after 15 days $(0.14 \% \mathrm{v} / \mathrm{v})$ and reached up to $0.76 \% \mathrm{v} / \mathrm{v}$ after 90 days. Sensitivity of yeast cells to ethanol marginally increased on decreasing the $\mathrm{pH}$ from 6.0-3.0. During fermentation process, $\mathrm{CO}_{2}$, alcohol and glycerol produced is proportional to the amount of sugar fermented. The yeast strain produced large amount of glycerol at the expense of ethanol represent an advantageous alternative for the development of beverages with low ethanol content versus physical process which alter the organoleptic properties of the final product (Jairath et al., 2012). The $\mathrm{CO}_{2}$ pressure 0.5 bar started building after 15 days and increased to 1.25 after 60 days and after 90 days reached up to 1.35 bar. Viable cell count increased from 5.83 (Log no. of cells) to 8.54 (Log no. of cells) at the end of 90 days. The shelf life is standardized on the basis of alcohol production $<1.0 \%$. Thus, shelf life of beverage has been found to be 90 days. Thus this technology will not only help in reducing the wastage of the citrus fruits, by removing the bitterness, but will also help in overcoming the problem of storage of beverages for a long period of time.

Effect of storage time on organoleptic properties of beverage: The beverage has been rated as liked very much during sensory evaluation due to its effervescence due to production of $\mathrm{CO}_{2}$ by $C$. lusitaniae, improved tangy taste, color, appearance, texture, and aroma as well as enriched with the nutrients and typical flavour of the fruits. $\mathrm{CO}_{2}$ is an antimicrobial agent itself acting as a critical solvent and week organic acid (upon dissolution) penetrating plasma membrane and acidifying cell anterior of microorganism, thus responsible for enhancing shelf life of the beverage. The effectiveness of carbonation is the main factor in determining the quality and consumer acceptance of final beverage (Singh, 2015). As compared to fruit juices the formulation of low alcoholic self carbonated beverage offers more variety of flavour, nutrients, long shelf life and other physiological benefits with greater margin of safety in a fermented drink. The fermentation conditions and technology is simple and can be adopted at small and pilot scale. Grapefruit beverages were analyzed by Panellists for sensory scores till period of three months (Table 3). No significant difference in appearance, color, aroma, bouquet, body, flavour, astrin- 
gency and overall acceptability of grapefruit was recorded.

Cook et al., 2003 found that somatosensory tactile stimuli interact with taste and aroma and hence modulating their perception. The beverage had pleasing effervescent sparkling appearance. The storage temperature can greatly affect the way beverage tastes and smells. Lower temperatures will emphasize acidity and tannins while muting the aromatics. Higher temperatures will minimize acidity and tannins while increasing the aromatics (skarletbeveragecompany.com).The presence of yeast in beverage gave a desirable freshness to the fermented beverage due to production of carbon dioxide (Pandove et al., 2016).

\section{Conclusion}

In the low alcoholic naturally carbonated fermented debittered Grapefruit beverage,the percentage decrease in naringin was 43.22 percent as it decreased gradually from 643.20 to 365.20 ppm after 90 days. This may be due to the production of enzyme naringinase by $C$. lusitaniae. The alcohol production started after 15 days $(0.14 \%$ $\mathrm{v} / \mathrm{v}$ ) and reached up to $0.76 \% \mathrm{v} / \mathrm{v}$ after 90 days. During fermentation process, $\mathrm{CO}_{2}$, alcohol and glycerol produced is proportional to the amount of sugar fermented. Naturally produced $\mathrm{CO}_{2}$ by $C$. lusitaniae during fermentation adds effervescence, sparkle, tangy taste to the beverage in addition to its antimicrobial properties. Thus, bioenzymatic debittering by $C$. lusitaniae may become the new direction of citrus juice processing in the future, due to its economical viability with strong ability to remove the bitter taste from citrus juice beverage.

\section{REFERENCES}

Ahmed, M., Ahmad, A., Chatha, Z. A. and Dilshad, S. M. R. (2008). Studies on preparation of ready to serve mandarin (Citrus reticulata) diet drink. Pakistan Journal of Agricultural Sciences, 45:470-76.

Akhtar, S., Riaz, M., Ahmad, A. and Nisar (2010). A physicochemical, microbiological and sensory stability of chemically preserved mango pulp. Pakistan Journal of Botany, 42:853-62.

Anonymous (2010). Available at www.marketpublisher.com.

Anonymous (2013). Available at archive.indianexpress.com.

AOAC (1999). Official Methods of Analysis, 16th Edition, 5th Reversion, International, Gaithersburg MD, method, 942.15.

AOVC (1996). Methods of vitamin assay, Association of Vitamin Chemists Inc. (Ed.) Interscience Publishers, 306-312.

Banerjee, G. D. (2009). Poised for a golden revolution. Times Agriculture Journal, 01 April. Critical Reviews in Biotechnology, 16:145-55.

Chandler, B. V. and Nicol, K. J. (1975). Some relationships of naringin: their importance in orange juice bitterness. CSIRO Food Res Quart, 35:79-88.

Chien, P. J., Sheu F. and Shiyu, Y. T. (2001). Monitoring enzy- matic debittering in grapefruit juice by high performance liquid chromatography. Journal of Food and Drug Analysis, 9:115-20.

Cook, D. J., Hollowood, T. A., Linforth, R. S. T. and Taylor, A. J. (2003).Oral shear stress predicts flavour perception in viscous solutions, Chemical Senses, 28:11-23.

Davis, W. B. (1947). Determination of flavanones in citrus fruits. Analytical Chemistry, 19:476-478.

Dubois, M., Gills, K. A., Hamilton, J. K., Roberts, P.A. and Smith, F. (1956). Colorimetric method for determination of sugars andrelated substances, Analytical Chemistry, 28:350 $-56$.

Jairath, S., Sahota, P. P. and Pandove, G. (2012). Preparation of non-alcoholic naturally carbonated beverage using yeast isolate from whey beverage. Czech Journal of Food Science, 30:135-43.

Khandelwal, P., Kumar, V., Das, N. and Tyagi, S. M. (2006). Development of a process for preparation of pure and blended kinnow wine without debittering kinnow mandarin juice. Internet Journal of Food Safety, 8:24-29.

Konno, A., Misaki, M., Toda, J., Wada, T. and Yasumatsu, K. (1982). Bitterness reduction of naringin and limonin by $\beta$ cyclodextrin. Agricultural and Biological Chemistry, 46:2203-08.

Miller, G. L. (1959). Use of dinitrosalicylic acid reagent for determination of reducing sugar. Analytical Chemistry, 31:426-428.

Pandove, G., Sahota, P., Gupta, N. and Singh, P. (2016). Production of low-alcoholic naturally carbonated fermented debittered beverage from W. Murcott mandarin (Citrus reticulata) by naringinase producing yeast. Journal of Food, Agriculture and Environment 14: 30 - 34

Sahota, P. and Pandove, G. (2010). Growth kinetics of Yeast for production of low alcoholic beverage from carrot: amla juice. Sciencia Acta Xaveriana: An International Research Journal of Basic And Applied Sciences, 1:17-33.

Sahota, P., Sharma, S. and Pandove, G. (2013). A novel bioprocessing debittering fermentation technology by clavispora lusitaniae mutant. Research Journal of Biotechnology, $8(7): 12-17$

Sarolia, D. K. and Mukherjee, S. (2002). Comparative efficiency of different preservation methods in keeping quality of lime (Citrus aurantifolia) swingle juice during storage. Haryana Journal of Horticultural Sciences, 31:185-88.

Silver, H.J., Dietrich, M.S. and Niswender, K. D. (2011). Effects of grapefruit, grapefruit juice and water preloads on energy balance, weight loss, body composition, and cardio metabolic risk in free-living obese adults. Nutrition \& Metabolism, 8: 8.

Singh, P. (2015). Fermentative production of debittered kinnow beverage using $\alpha$-L-Rhamnosidase producingyeast $\mathrm{Ph} . \mathrm{D}$ Thesis, Punjab Agricultural University,Ludhiana,Punjab.

Singh, P., Sahota, P. P., Bhadra, F. and Singh, R. K. (2015). Optimization, production and scale up of debittered kinnow beverage by $\alpha$-L-rhamnosidase producing yeast. Emirates Journal of Food and Agriculture, 27:548-555.

Yadav, V., Pramod, K., Yadav, L., Yadav, S. and Yadav, K.D.S. (2010). $\alpha$-L-Rhamnosidase: A review. Process Biochemistry, 45:1226-35. 